Review

\title{
A review of significant factors in the synthesis of hetero-structured dumbbell-like nanoparticles
}

\author{
Qifu Huang, Wenzhi Li *, Qizhao Lin \#, Dong Pi, Chao Hu, Chunyu Shao, Haitao Zhang \\ Department of Thermal Science and Energy Engineering, School of Engineering Science, University of Science and Technology of China, Hefei 230026, \\ Anhui, China
}

\section{A R T I C L E I N F O}

Article history:

Received 9 January 2016

Accepted 24 February 2016

Published 5 May 2016

\section{Keywords:}

Dumbbell-like nanoparticle

Catalyst synthesis

Catalytic combustion

Catalytic oxidation

\begin{abstract}
A B S T R A C T
This paper reviews several important factors that influence the synthesis of dumbbell-like nanoparticles, which can significantly enhance the catalyst activity in catalytic combustion. The dumbbell-like nanoparticles discussed in this article refer to a hetero-structure with two nanoparticles of different materials in contact with each other. This nanostructure can be considered as a special intermediate between individual spherical nanoparticles and a core-shell nanostructure. Therefore, the synthesis of dumbbell-like nanoparticles is more difficult than other structures. The controllability of the synthesis process, the nanoparticle size and size distribution, and the morphology of the final products depend on many factors: the seed size and size ratio could be used to influence the controllability of epitaxial growth. The component sizes and size distribution could be varied by carefully controlling the reaction temperature and reaction time. The morphology of the dumbbell-like nanoparticles is closely related to the solvent polarity, the precursor ratio, the lattice mismatch between the two components, and the surfactant concentration. Some related synthesis methods are also briefly introduced in each section to facilitate understanding. This summary will benefit the development of new dumbbell-like nanoparticles with various components, which have great potential in catalytic combustion of more dysoxidizable gases.
\end{abstract}

(C) 2016, Dalian Institute of Chemical Physics, Chinese Academy of Sciences. Published by Elsevier B.V. All rights reserved.

\section{Introduction}

A dumbbell-like nanoparticle consists of a strongly interacting hetero-structure with one nanoparticle at one end and another at the other end. The two different functional nanoparticles in intimate contact with each other look like a dumbbell (Fig. 1(a)) [1]. In some articles, particles with this type of structure are also called peanut-like particles [2]. This kind of binary hybrid nanoparticles are of interest because of their unique electronic [3-7], magnetic [8-10], optical [11-14], and catalytic $[15,16]$ properties, which are not present in the indi- vidual component nanoparticles. These properties result from the electronic communication across the junction between the two components. In contrast to other structures such as core-shell nanoparticles, in which the core and its interface is surrounded by the shell, in dumbbell-like nanoparticles the two functional surfaces of the two components and their active interface are all exposed; this enhances their catalytic activity and their usefulness as multifunctional probes for diagnostic and therapeutic applications $[17,18]$. Because the relative positions of each component in dumbbell-like nanoparticles can be fixed, a coordinated distribution between the two components

\footnotetext{
* Corresponding author. Tel: +86-551-63600786; Fax: +86-551-63600786; E-mail: liwenzhi@ustc.edu.cn

\# Corresponding author. Tel: +86-551-63600430; E-mail: qlin@ustc.edu.cn

This work was supported by the National Natural Science Foundation of China (51376171) and Science and Technological Fund of Anhui Province for Outstanding Youth (1508085J01). 

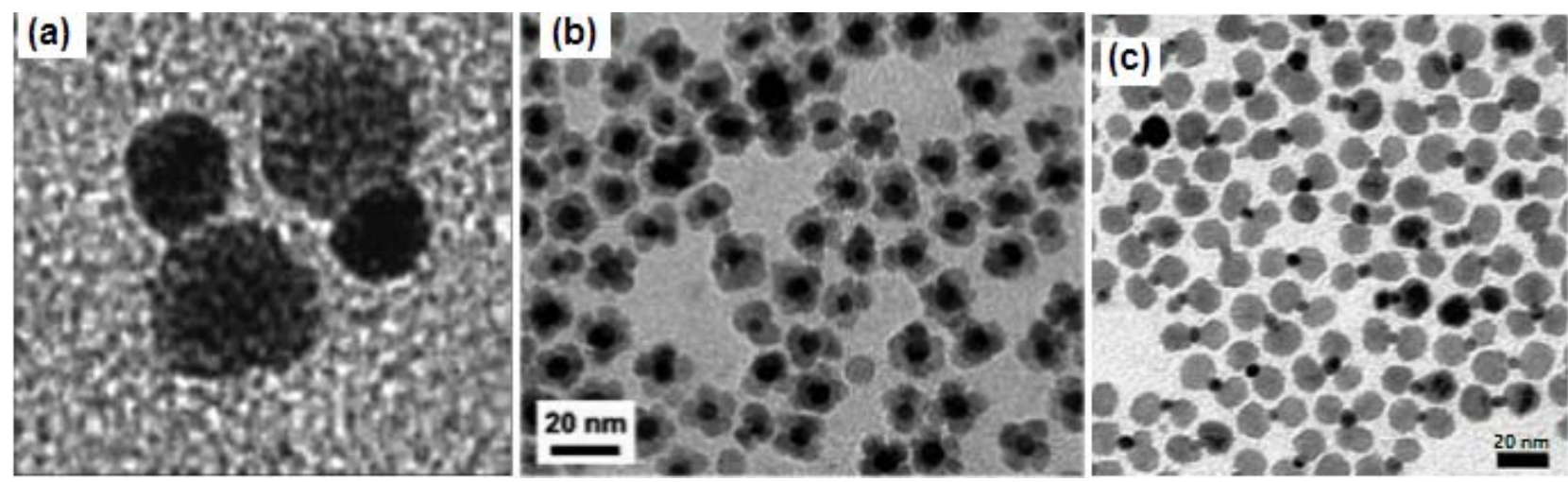

Fig. 1. (a) Transmission electron microscopy (TEM) image of the $\mathrm{Ag}_{-} \mathrm{Fe}_{3} \mathrm{O}_{4}$ dumbbell-like nanoparticles (reproduced with permission from Ref. [1]); (b) TEM image of flower-like $\mathrm{Au}-\mathrm{Fe}_{3} \mathrm{O}_{4}$ nanoparticles (reproduced with permission from Ref. [3]) ; (c) $\mathrm{Fe}_{3} \mathrm{O}_{4}-\mathrm{Au}-\mathrm{Fe}_{3} \mathrm{O}_{4}$ ternary hybrid nanoparticles (reproduced with permission from Ref. [2]).

in catalytic combustion of $\mathrm{CO}[1,19]$ and other gases is possible, and sintering can thus be minimized. For example, Au nanoparticles are normally chemically inert and do not catalyze the CO oxidation reaction, but show high catalytic activity after they are deposited on a metal-oxide support [20,21]. This enhancement in catalytic activity is believed to result from the electron transfer between the oxide support and the adjacent $\mathrm{Au}$ nanoparticles [22-24]. In a dumbbell-like structure, the catalytic nanoparticles can not only have a better junction effect because they are in intimate contact within each pair but they are also stable at higher temperatures because of their coordinated distribution and fixed positions [25].

Dumbbell-like nanoparticles can be considered as an intermediate between individual component nanoparticles and core-shell nanoparticles. Dumbbell-like nanoparticles are generally synthesized by epitaxial growth of one component nanoparticle on another component nanoparticle, which is called the seed nanoparticle. This is similar to the procedure of synthesizing core-shell nanoparticles, but the nucleation must be controlled appropriately to make the nucleation anisotropically centered on one specific crystal plane around the seeding nanoparticles, which is different from the uniform distribution in core-shell structures. Therefore, heterogeneous nucleation must be promoted and homogeneous nucleation must be suppressed for the successful synthesis of dumbbell-like nanoparticles.

One of the benefits of this special structure and strong interface interactions is that both components in the structure can be modified by electron transfer across the interface, making dumbbell-like nanoparticles highly active at relatively low temperatures for the catalytic oxidation of some exhaust gases, such as CO. Unfortunately, because of the particularity of the structure and the stringent requirements for an appropriate nucleation described above, only a few dumbbell-like nanoparticles have been successfully synthesized to date, including $\mathrm{Au}(\mathrm{Ag}, \mathrm{Pt}, \mathrm{Pd})-\mathrm{Fe}_{3} \mathrm{O}_{4}\left(\mathrm{Co}_{3} \mathrm{O}_{4}\right)$ [2,3,17,25-28], $\mathrm{Au}-\mathrm{PbS}(\mathrm{PbSe})$ [2], FePt-CdS [11], and Cu-Ag [29]; most of these contain noble metal nanoparticles and magnetic nanoparticles. The application of dumbbell-like nanoparticles to the catalytic combustion of gases is limited to very few studies, almost all of which focus on CO oxidation, which can be oxidized by many other catalysts at very low temperatures, even dozens of degrees below zero [30]. Therefore, the advantages of dumbbell-like nanoparticles cannot be fully appreciated by studying the catalytic oxidation of $\mathrm{CO}$. Other gases including $\mathrm{CH}_{4}$, which are more difficult to oxidize catalytically at relatively low temperatures, have not been studied using these catalysts. This research gap is mostly owing to the difficulty in synthesizing dumbbell-like nanoparticles using a wide variety of chemical elements. Therefore, it is necessary to know what the difficulties are and what factors can influence the synthesis results.

In this review we have summarized some significant factors that influence the preparation of dumbbell-like nanoparticles, which might be helpful in the development of dumbbell-like nanoparticles composed of other chemical elements. These new structures might show higher catalytic activity and could be used for the catalytic combustion of other gases.

\section{Influence of nanoparticle size on the controllability of epitaxial growth}

\subsection{Influence of seed size}

Smaller metal particles with a higher specific surface area and larger contact region with the reactants would not only enhance the catalytic activity, but could also facilitate the synthesis of dumbbell-like nanoparticles if used as seed nanoparticles [31-36].

Wang's group [25] introduced a general approach to noble metal-metal oxide dumbbell-like nanoparticles through organic solvothermal synthesis (Scheme 1). During the seed-mediated growth, after thermal decomposition, metal oxides oxidized from metal carbonyls grown over the noble metal seeds, followed by oxidation in air. They succeed in preparing nanoparticles with diverse materials, including the noble metals $\mathrm{Au}$, $\mathrm{Ag}, \mathrm{Pt}$, or $\mathrm{Au}-\mathrm{Ag}$ alloys and oxides of $\mathrm{Fe}$ or $\mathrm{Co}$, which all exhibited enhanced catalytic activity toward CO oxidation. They pointed out that monodisperse seeding nanoparticles with the right size and surface were crucial in making dumbbell-like nanoparticles. The larger particles tended to precipitate as the 


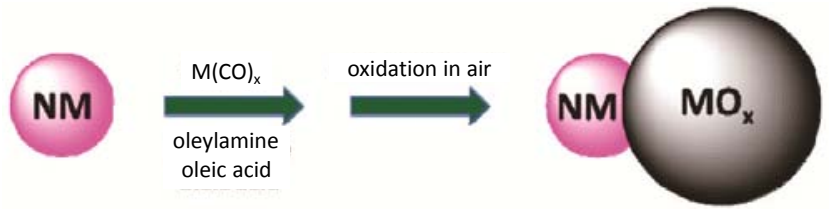

Scheme 1. Seed-mediated growth for noble metal-metal oxide nanoparticles. Reproduced with permission from Ref. [25].

metal oxide nanoparticles grow on them. To have good control of the epitaxial growth, the seed sizes should be below $10 \mathrm{~nm}$.

\subsection{Influence of size ratio}

In another synthesis of exchange-coupled nanocomposite magnets through nanoparticle self-assembly by Zeng et al. [37], hexane dispersions of $\mathrm{FePt}$ and $\mathrm{Fe}_{3} \mathrm{O}_{4}$ nanoparticles with selected concentrations, volumes, and sizes were mixed under ultrasonic agitation, followed by evaporation of the hexane or addition of ethanol. Ultimately, these two kinds of nanoparticles were converted into $\mathrm{FePt}_{-} \mathrm{Fe}_{3} \mathrm{Pt}$ nanocomposites. They fixed the mass ratio of $\mathrm{Fe}_{3} \mathrm{O}_{4}$ and $\mathrm{FePt}$ to $1: 10$ but the sizes were different, and the TEM images of the resulting binary assemblies are shown in Fig. 2 [37]. We can see that when the sizes of $\mathrm{Fe}_{3} \mathrm{O}_{4}$ and $\mathrm{FePt}$ were both $4 \mathrm{~nm}$, almost one $\mathrm{Fe}_{3} \mathrm{O}_{4}$ nanoparticle was connected with one FePt nanoparticle (Fig. 2(a)); when the $\mathrm{Fe}_{3} \mathrm{O}_{4}$ nanoparticle was enlarged to $8 \mathrm{~nm}$, each large nanoparticle of $\mathrm{Fe}_{3} \mathrm{O}_{4}$ was surrounded by 6-8 small $\mathrm{FePt}$ nanoparticles (Fig. 2(b)). It follows logically that, because the mass ratio was fixed, a larger $\mathrm{Fe}_{3} \mathrm{O}_{4}$ nanoparticle should be in contact with more FePt particles. However, when the size of the $\mathrm{Fe}_{3} \mathrm{O}_{4}$ particles was changed to $12 \mathrm{~nm}$, a clear phase segregation appeared between the two components (Fig. 2(c)). It is apparent that the particle size ratio has a great impact on the ordering of nanoparticles [38] and the structure formed.

\section{Influence of reaction temperature on component size}

We have already discussed that the seed size could influence the nanoparticle ordering and determine the successful formation of dumbbell-like structures. The sizes of the components in a dumbbell-like structure could also be influenced by the reaction temperature.
Table 1

Average size of Au nanoparticles synthesized at different temperatures. Reproduced with permission from Ref. [39].

\begin{tabular}{lc}
\hline Reaction temperature $\left({ }^{\circ} \mathrm{C}\right)$ & Average Au NP size $(\mathrm{nm})$ \\
\hline 2 & 9.5 \\
10 & 8.1 \\
15 & 7.3 \\
20 & 6.4 \\
25 & 5.3 \\
35 & 3.3 \\
40 & 2.4 \\
\hline
\end{tabular}

\subsection{Influencing the size of noble metal seed}

The reaction temperature could influence the sizes of noble metal seeds $[3,25,28,39]$. For example, in Wang's experiment [25] mentioned above, they mixed platinum acetylacetonate [Pt(acac)2, "acac" refers to acetylacetonyl], 1-octadecene (ODE), oleylamine, and oleic acid, then the hexane solution of $\mathrm{Fe}(\mathrm{CO})_{5}$ was quickly injected into the hot mixture solution at $180^{\circ} \mathrm{C}$. After heating the solution to $200^{\circ} \mathrm{C}$ and keeping it at that temperature for $1 \mathrm{~h}$ before cooling to room temperature, they obtained 3-nm Pt nanoparticles; if the $\mathrm{Fe}(\mathrm{CO})_{5}$ solution was injected at 160 and $120^{\circ} \mathrm{C}$ they obtained 5- and 7-nm Pt nanoparticles, respectively.

In a facile synthesis of monodisperse Au nanoparticles reported by Peng's group [39], they used oleylamine (OAm) as a nanoparticle stabilizer, tert-butylamine-borane complex as a reducing agent, and tetralin as solvent. They prepared Au nanoparticles through a burst nucleation with sizes tunable from 1 to $10 \mathrm{~nm}$ by carefully controlling the reaction temperature at which the reducing solution was injected into the precursor solution. The reaction temperatures and the resulting sizes of the Au nanoparticles are listed in Table 1 [39]. It is apparent that there is a linear correlation between the reaction temperature and the nanoparticle size. This formation of Au nanoparticles can be explained by the classic La Mer theory [40,41]: injection of the reducing agent into the precursor solution at a relatively high temperature results in the burst nucleation consuming most of the precursors, leading to fast nucleation and growth processes, and ultimately produces smaller $\mathrm{Au}$ nanoparticles.
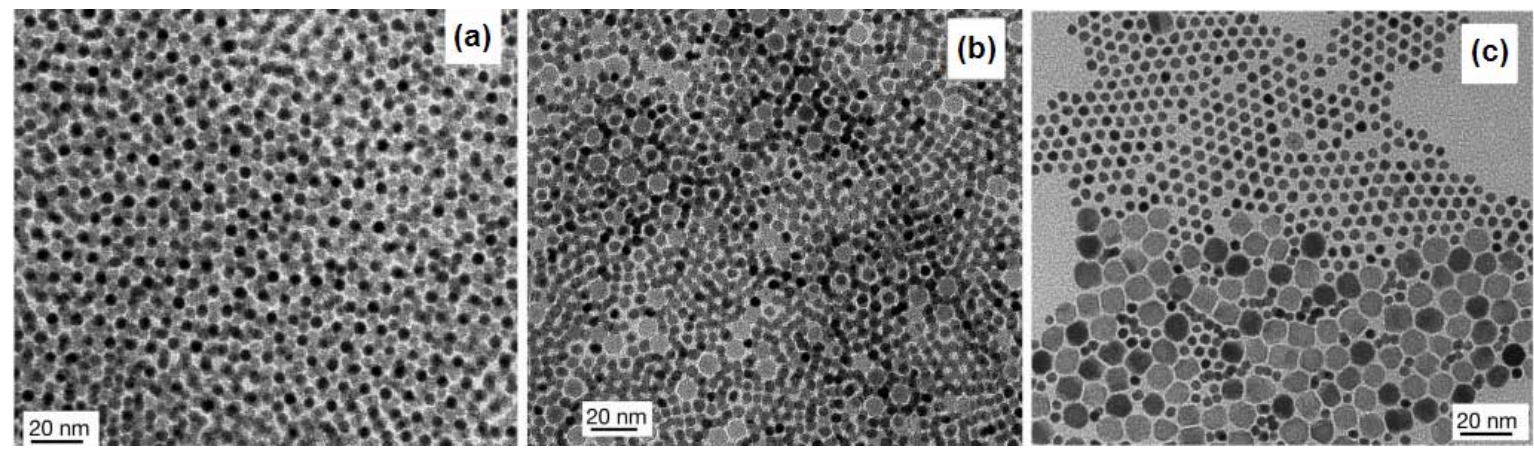

Fig. 2. TEM images showing binary nanoparticle assemblies. (a) $\mathrm{Fe}_{3} \mathrm{O}_{4}(4 \mathrm{~nm}): \mathrm{Fe}_{58} \mathrm{Pt}_{42}(4 \mathrm{~nm})$ assembly; (b) $\mathrm{Fe}_{3} \mathrm{O}_{4}(8 \mathrm{~nm}): \mathrm{Fe}_{58} \mathrm{Pt}_{42}(4 \mathrm{~nm})$ assembly; (c) $\mathrm{Fe}_{3} \mathrm{O}_{4}(12 \mathrm{~nm}): \mathrm{Fe}_{58} \mathrm{Pt}_{42}(4 \mathrm{~nm})$ assembly. All with a fixed mass ratio. Reproduced with permission from Ref. [37]. 


\subsection{Influencing the size of metal oxide nanoparticle}

Even though the size of the metal oxide nanoparticles is not normally tuned by changing the reaction temperature, it has been observed that, in the synthesis of magnetite nanoparticles using thermal decomposition of the metal precursor $[42,43]$, the metal oxide nanoparticles were bigger as the temperature increased, which is different from the noble metal seeds mentioned above. The thermal decomposition procedure is similar to epitaxial growth of metal oxide nanoparticles on noble metal seeds for the synthesis of dumbbell-like nanoparticles [1]. In the synthesis of $\mathrm{Fe}_{3} \mathrm{O}_{4}$ nanoparticles reported by Sun et al. [42] (Scheme 2), they mixed Fe(acac) 3 , 1,2-hexadecanediol, oleic acid, oleylamine, and phenyl ether, and then heated the mixture to $200{ }^{\circ} \mathrm{C}$. The reaction mixture was then heated to reflux at $265^{\circ} \mathrm{C}$ and 4-nm nanoparticles were obtained. However, when they changed the phenyl ether to benzyl ether (which has a higher boiling temperature than phenyl ether) and changed the reflux temperature to $300{ }^{\circ} \mathrm{C}$, they obtained 6-nm nanoparticles.

\subsection{Influencing the size distribution}

The reaction temperature could also have a strong influence on the size distribution during the epitaxial nucleation and growth process of the metal oxide on noble metal seeds. In a typical synthesis of magnetic-metallic $\left(\mathrm{XFe}_{2} \mathrm{O}_{4}-\mathrm{Au}, \mathrm{X}=\mathrm{Fe}, \mathrm{Mn}\right.$, Co) dumbbell-like nanoparticles, Shi's group [2] pointed out that an inappropriate temperature-rise period would give a much broader size distribution of the nanoparticles. They used a two-stage heating strategy to synthesize hybrid nanoparticles, including $\mathrm{Au}-\mathrm{Fe}_{3} \mathrm{O}_{4}$ dumbbell-like nanoparticles. The dumbbell-like nanoparticles were prepared by decomposition of iron acetylacetonate $\left(\mathrm{Fe}(\mathrm{acac})_{3}\right)$ on the surface of $\mathrm{Au}$ nanoparticles in octyl ether, with the presence of oleic acid and oleylamine. Octyl ether is a high-boiling-point solvent; as such, the mixture could be heated to $205^{\circ} \mathrm{C}$ and kept at that temperature for $2 \mathrm{~h}$ before heating to reflux at a temperature as high as $300{ }^{\circ} \mathrm{C}$. If the reaction mixture was heated to $300{ }^{\circ} \mathrm{C}$ directly, a wide size distribution of the dumbbell-like nanoparticles resulted. A temperature of $200{ }^{\circ} \mathrm{C}$ was first used for $2 \mathrm{~h}$ because it is slightly higher than the decomposition temperature of

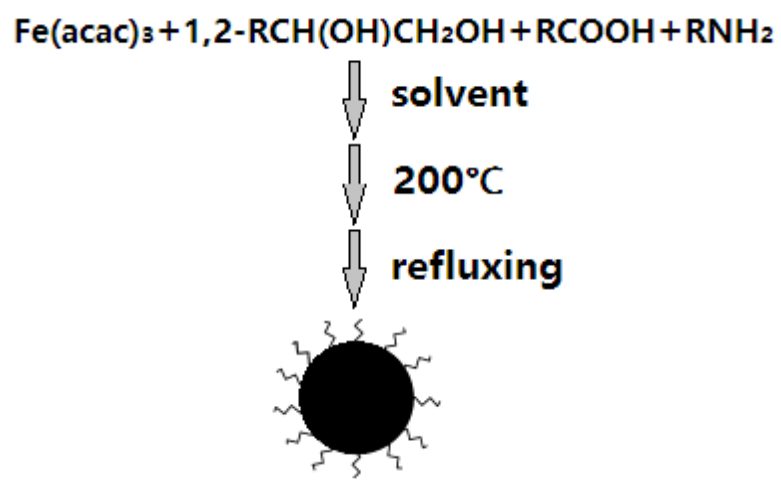

Scheme 2. Organic phase process for making monodisperse $\mathrm{Fe}_{3} \mathrm{O}_{4}$ nanoparticles. Reproduced with permission from Ref. [42].
$\mathrm{Fe}(\mathrm{acac})_{3}$, which was used as the precursor of $\mathrm{Fe}_{3} \mathrm{O}_{4}$. At this temperature the concentration of free metal ions was not so high, resulting in heterogeneous nucleation and slow growth of the nuclei during this period. After the reaction mixture was heated to reflux at a relativity high temperature of approximately $300{ }^{\circ} \mathrm{C}$, those nuclei grew substantially. Thus, the twostage temperature could separate the nucleation and growth process of the metal oxide nanoparticles on the noble metal seeds.

This relationship between the temperature and size distribution was also reported by Sun's group [42] in the synthesis of monodisperse magnetite $\left(\mathrm{Fe}_{3} \mathrm{O}_{4}\right)$ nanoparticles, using a similar strategy of high-temperature solution phase reaction of Fe(acac) 3 with 1,2-hexadecanediol in the presence of oleic acid and oleylamine. They obtained $\mathrm{Fe}_{3} \mathrm{O}_{4}$ nanoparticles with a size distribution of 4 to $15 \mathrm{~nm}$ when the temperature was raised rapidly from room temperature to reflux; and they succeed in preparing monodisperse $\mathrm{Fe}_{3} \mathrm{O}_{4}$ nanoparticles with good size control of 4 or $6 \mathrm{~nm}$ using the same two-stage temperature procedure at two different reflux temperatures.

\section{Influence of reaction time on component size}

\subsection{Influence at a liquid-liquid interface}

In contrast to the most common methods to produce dumbbell-like nanoparticles using organic solvents [2,3,27], Gu's group [17] introduced a new method to create dumbbell-like nanostructures at a liquid-liquid interface between an organic solvent and an aqueous solution. At this interface, nanoparticles could self-assemble to form "colloidosomes", and every nanoparticle forming the colloidosomes would be partially exposed. Heterogeneous reaction takes place on these exposed surfaces to produce dumbbell-like nanoparticles composed of two distinct nanospheres. In a typical synthesis of $\mathrm{Ag}-\mathrm{Fe}_{3} \mathrm{O}_{4}$ dumbbell-like nanoparticles, they dissolved the as-prepared nanoparticles of $\mathrm{Fe}_{3} \mathrm{O}_{4}$ [43] into an organic solvent (e.g., dichlorobenzene, dichloromethane, hexane, or dioctyl ether) to form a solution, and then the solution was added into an aqueous solution of silver nitrate. The mixture was treated under ultrasonic emulsification to form a stable emulsion $[44,45]$ of the two solutions. The dumbbell-like nanoparticles were obtained after $30 \mathrm{~min}$, as illustrated in Scheme 3 [17].

The nucleation of the $\mathrm{Ag}$ on $\mathrm{Fe}_{3} \mathrm{O}_{4}$ nanoparticles was observed using TEM. As shown in Fig. 3 [17], the size of the $\mathrm{Fe}_{3} \mathrm{O}_{4}$ nanoparticles was $8 \mathrm{~nm}$ (Fig. 3(a)) before the nucleation of Ag. After a reaction period of $10 \mathrm{~min}$, the $\mathrm{Ag}$ spheres appeared on the surface of the $\mathrm{Fe}_{3} \mathrm{O}_{4}$ nanoparticles and had a size of $3 \mathrm{~nm}$ (Fig. 3(b)); when the reaction was stopped after $30 \mathrm{~min}$ the $\mathrm{Ag}$ spheres had grown to $5.5 \mathrm{~nm}$ (Fig. 3(c)) but the size of the $\mathrm{Fe}_{3} \mathrm{O}_{4}$ nanoparticles did not change during the reaction period.

This can be explained by the formation process of the $\mathrm{Ag}$ nanoparticle. Because the $\mathrm{Fe}_{3} \mathrm{O}_{4}$ nanoparticle was not completely covered by the surfactant molecules, only a few Fe(II) sites could act as the catalytic center for the reduction of $\mathrm{Ag}^{+}$, i.e., the $\mathrm{Fe}_{3} \mathrm{O}_{4}$ nanoparticle was used for seeding an $\mathrm{Ag}$ nanoparticle. Further reduction of $\mathrm{Ag}^{+}$could take place at the initial 


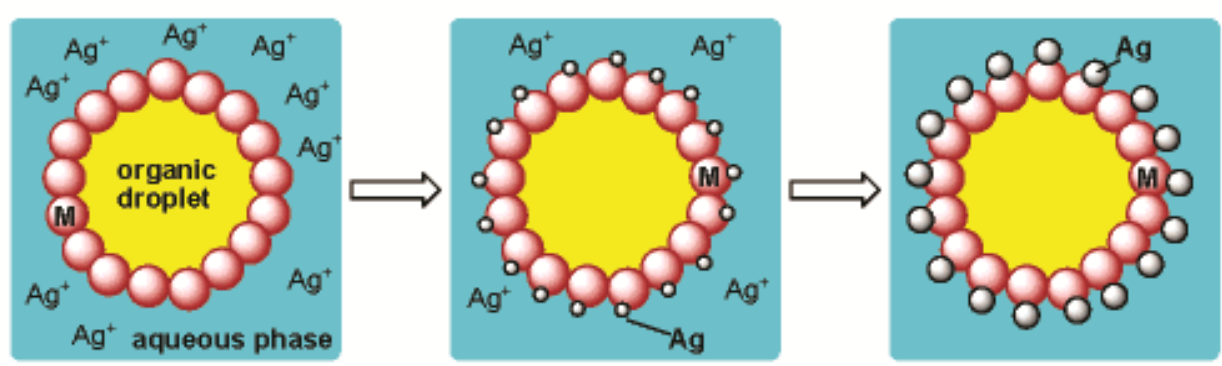

Scheme 3. Formation of dumbbell-like nanoparticles at a liquid-liquid interface. Reproduced with permission from Ref. [17].

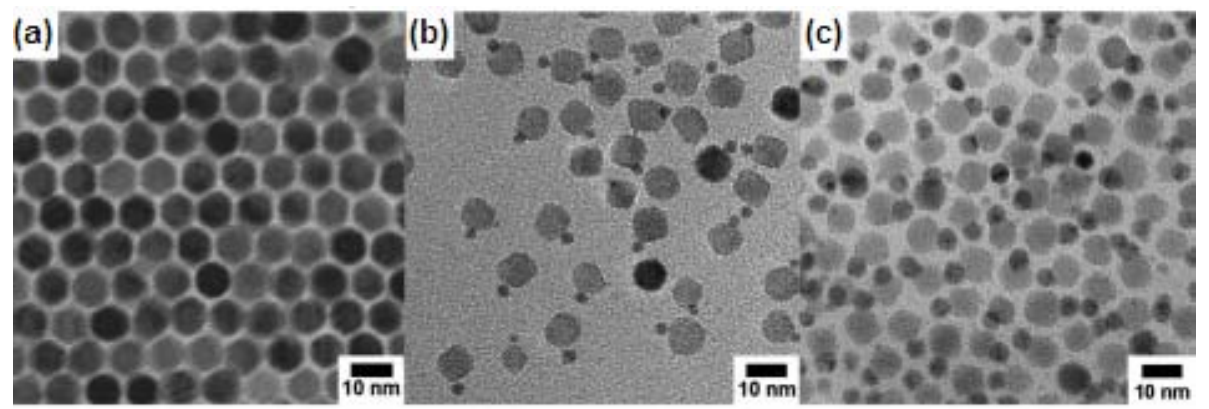

Fig. 3. TEM images of (a) the as-prepared $\mathrm{Fe}_{3} \mathrm{O}_{4}$ nanoparticles and the $\mathrm{Fe}_{3} \mathrm{O}_{4}-\mathrm{Ag}$ heterodimers (b) after reaction for 10 min and (c) after the reaction was stopped at 30 min. Reproduced with permission from Ref. [17].

Ag nucleation sites. Therefore, the diameter of the Ag nanoparticles increased with the reaction time as they grew on the $\mathrm{Fe}_{3} \mathrm{O}_{4}$ seeds.

\subsection{Influencing difference between liquid-liquid interface formation and burst nucleation}

Interestingly, in the synthesis of Au nanoparticle seeds reported by Peng et al. [39], the size of the Au nanoparticle was not dependent on the reaction time. They used a tert-butylamine-borane complex as a reducing agent and hydrogen tetrachloroaurate(III) hydrate as a precursor in tetralin and oleylamine to produce monodisperse $\mathrm{Au}$ nanoparticles. They removed the same amount of the reaction mixture at different reaction times during the 1 -h reaction process, and found little size change. This may be because the reaction rate was different to the nucleation of $\mathrm{Ag}$ on $\mathrm{Fe}_{3} \mathrm{O}_{4}$. In this synthesis, the burst nucleation occurred immediately and consumed most of the precursors after the reducing agent was injected; thus, the nucleation and growth processes were very fast and independent of the reaction time. That is to say, depending on the actual synthesis method, the reaction time may have an influence on the component size or not.

\section{Influence of reaction solvent polarity on the morphology}

The morphology of the nanoparticles in a dumbbell-like structure is more important than the size. This is also a more challenging synthetic process. The most common influencing factor that differentiates the dumbbell-like nanoparticles from ordinary spherical or core-shell nanoparticles is the polarity of solvent used in the reaction.

\subsection{Electron transfer in dumbbell-like structure formation}

The formation of a dumbbell-like nanoparticle results from the epitaxial growth of one component nanoparticle on another component nanoparticle. A suitable electron transfer results in dumbbell-like structures instead of core-shell structures. For example, in the synthesis of $\mathrm{Au}-\mathrm{Fe}_{3} \mathrm{O}_{4}$ dumbbell-like nanoparticles, as the $\mathrm{Fe}_{3} \mathrm{O}_{4}$ nanoparticles nucleate on $\mathrm{Au}$ nanoparticles, the polarized plane [3] induces a change in the charge at the interface, and the free electrons from the $\mathrm{Au}$ nanoparticles will compensate for that charge change. However, one Au nanoparticle only has a limited amount of electrons, so the compensation could only take place at only one facet of the Au nanoparticle, resulting in electron deficiency at other facets, which is not suitable for multi-nucleation. Therefore, only dumbbell-like structure can be produced. If the $\mathrm{Au}$ nanoparticle has more electrons to compensate for the charge at the plane, the nucleation of $\mathrm{Fe}_{3} \mathrm{O}_{4}$ nanoparticles on $\mathrm{Au}$ seeds would occur at more facets of the Au nanoparticle. These extra electrons could be offered by more polar solvent in the synthesis.

\subsection{Influence of solvent polarity}

Yu et al. [3] prepared dumbbell-like $\mathrm{Au}-\mathrm{Fe}_{3} \mathrm{O}_{4}$ nanoparticles with 1-octadecene as solvent in the presence of oleic acid and oleylamine. They heated the mixture to reflux at a temperature of approximately $300{ }^{\circ} \mathrm{C}$ for the decomposition of iron pentacarbonyl over the surface of the Au nanoparticles, and then the mixture was oxidized at room-temperature in air, as illustrated in Scheme 4. After they changed the solvent from octadecene to diphenyl ether, which has a higher polarity, they obtained flower-like $\mathrm{Au}-\mathrm{Fe}_{3} \mathrm{O}_{4}$ nanoparticles (Fig. 1(b)) [3]. 


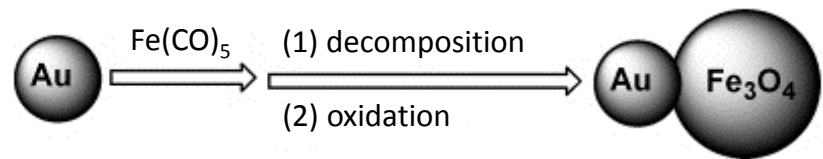

Scheme 4. Synthesis of $\mathrm{Au}-\mathrm{Fe}_{3} \mathrm{O}_{4}$ dumbbell-like nanoparticles using $\mathrm{Fe}(\mathrm{CO})_{5}$. Reproduced with permission from Ref. [3].

The research of Shi's group [2] is further proof of the influence of solvent polarity on the formation of dumbbell-like nanoparticles. They prepared dumbbell-like nanoparticles through the decomposition of $\mathrm{Fe}(\mathrm{acac})_{3}$ on the surfaces of $\mathrm{Au}$ nanoparticles in octyl ether, with the presence of oleic acid and oleylamine. When the solvent was changed to benzyl ether and phenyl ether, which contain aromatic rings and are good electron donors, core-shell particles were produced using the same procedure that resulted in dumbbell-like nanoparticles in octyl ether. If the solvent polarity was between octyl ether and benzyl ether or phenyl ether, such as octadecene, a mixture of dumbbell-like and core-shell structures was obtained. To further investigate this influence, they stopped the reaction halfway in phenyl ether or benzyl ether and obtained flower-like particles with several $\mathrm{Fe}_{3} \mathrm{O}_{4}$ "petals" surrounding the $\mathrm{Au}$ core. Core-shell particles should be ultimately produced if the reaction is not terminated. This observation is in accordance with the formation principle mentioned at the beginning of this section: high polarity solvents could give more electrons and contribute to the formation of additional $\mathrm{Fe}_{3} \mathrm{O}_{4}$ nuclei on the $\mathrm{Au}$ surface. Several $\mathrm{Fe}_{3} \mathrm{O}_{4}$ nuclei on the $\mathrm{Au}$ nanoparticle would result in a flower-like structure, and as these nuclei increase in size they would fuse together to form a shell, giving the final core-shell structure. However, if a solvent with mostly saturated hydrocarbon chains is used, further nucleation would not be possible after a single $\mathrm{Fe}_{3} \mathrm{O}_{4}$ nucleus is formed, because these solvents could not give enough electrons.

\section{Influence of precursor ratio on nanoparticle size and morphology}

\subsection{Influencing the nanoparticle size}

The size of dumbbell-like nanoparticles could be controlled by varying the molar ratio of one component to the seed component. In their research on using dumbbell-like $\mathrm{PtPd}-\mathrm{Fe}_{3} \mathrm{O}_{4}$ nanoparticles for electrochemical detection of $\mathrm{H}_{2} \mathrm{O}_{2}$, Sun et al. [46] obtained different sizes of $\mathrm{Fe}_{3} \mathrm{O}_{4}$ nanoparticles by controlling the molar ratio of $\mathrm{Fe}(\mathrm{CO})_{5}$ to $\mathrm{Pt}-\mathrm{Pd}$ seeds, in which $\mathrm{Fe}(\mathrm{CO})_{5}$ acted as the precursor of $\mathrm{Fe}$. $\mathrm{PtPd}-\mathrm{Fe}_{3} \mathrm{O}_{4}$ nanoparticles formed through controlled nucleation and growth in 1-octadecene in the presence of oleylamine and oleic acid followed by oxidation in air. But this influence of the precursor ratio on nanoparticle size was limited. Under some conditions the change in the precursor ratio could even affect the nanoparticle structures rather than the nanoparticle sizes [47].

\subsection{Influencing the morphology in the presence of sulfur}

Shi et al. [2] prepared binary and ternary hybrid nanocrys- tals by spontaneous epitaxial nucleation and growth of other components onto seed nanoparticles in organic solutions at a high temperature. Dumbbell-like nanostructures were present in the binary hybrid nanocrystals. Although they synthesized $\mathrm{Au}-\mathrm{Fe}_{3} \mathrm{O}_{4}$ dumbbell-like nanoparticles, even though $\mathrm{Fe}_{3} \mathrm{O}_{4}$ formed on gold nanoparticles all the time, they did not distribute evenly on every gold nanoparticle. They found that when a smaller amount of gold seeds than usual was used, a mixture of free $\mathrm{Fe}_{3} \mathrm{O}_{4}$ nanoparticles and dumbbell-like structures was produced.

They also prepared $\mathrm{Au}-\mathrm{PbS}$ and $\mathrm{Au}-\mathrm{PbSe}$ dumbbell-like nanoparticles [2]. For the synthesis of $\mathrm{Au}-\mathrm{PbS}$ dumbbell-like nanoparticles, $\mathrm{PbO}$ and oleic acid were first mixed in trioctylamine and heated to $120{ }^{\circ} \mathrm{C}$ to form a $\mathrm{Pb}$-oleate complex, then the mixture of the $\mathrm{Pb}$-oleate complex was cooled to about 100 ${ }^{\circ} \mathrm{C}$. A hexane solution of Au nanoparticles was then injected into the solution, followed by the addition of a sulfur solution in oleylamine and phenyl ether. The reaction mixture was heated to $150{ }^{\circ} \mathrm{C}$ and kept at that temperature for $1 \mathrm{~h}$. For the synthesis of nanoparticles with different morphologies, they kept the $\mathrm{PbO}: \mathrm{S}$ ratio at 3:1 while changing the amount of $\mathrm{Au}$ nanoparticles. When the ratio of Au:sulfur was 1:10, they obtained dumbbell-like nanoparticles (Fig. 4(a)); when the amount of $\mathrm{Au}$ nanoparticles was lowered to an Au:sulfur ratio of 1:20, they obtained ternary hybrid nanoparticles of $\mathrm{Fe}_{3} \mathrm{O}_{4}-\mathrm{Au}-\mathrm{Fe}_{3} \mathrm{O}_{4}$, in which every $\mathrm{Au}$ nanosphere was connected with two $\mathrm{PbS}$ nanospheres on opposite sides (Fig. 4(b)).

\subsection{Influencing difference between sulfur and solvent polarity}

It is clear that the precursor to seed ratio can influence the morphology of the resulting dumbbell-like $\mathrm{Au}-\mathrm{PbS}$ nanoparticles. In contrast to the thermal decomposition of an Fe precursor for the formation of $\mathrm{Au}-\mathrm{Fe}_{3} \mathrm{O}_{4}$, in which the morphology was mostly influenced by the polarity of the solvent, the changes in solvent did not affect the morphology of the $\mathrm{Au}-\mathrm{PbS}$ hybrid particles. Using different solvents with the same Au to precursor ratio, Shi's group [2] synthesized $\mathrm{Au}-\mathrm{PbS}$ nanoparticles with the same morphology. This was caused by the addition of sulfur; in the synthesis process sulfur tended to be adsorbed onto the surface of $\mathrm{Au}$, and at the same time sulfur would react with the $\mathrm{Pb}$-oleate complex. Thus, the element of sulfur was needed by both $\mathrm{Au}$ and $\mathrm{Pb}$-oleate simultaneously, and the competition finally resulted in the combination of $\mathrm{PbS}$ and $\mathrm{Au}$ through the nucleation of $\mathrm{PbS}$ on the surface of $\mathrm{Au}$. In this way both the $\mathrm{Pb}$-oleate complex and $\mathrm{Au}$ were satisfied. So
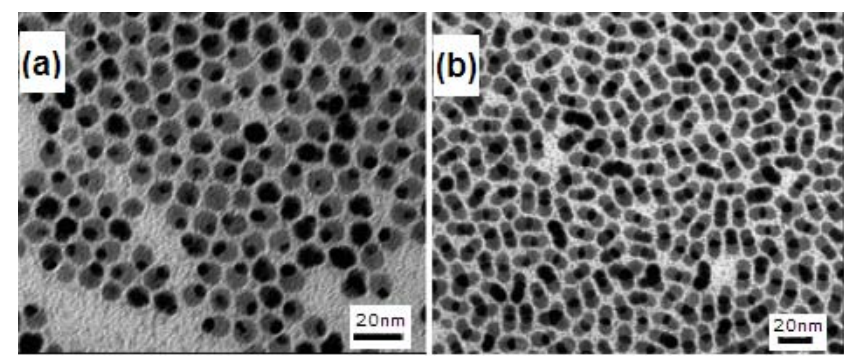

Fig. 4. Different morphologies with an Au:S ratio of (a) 1:10 and (b) 1:20. Reproduced with permission from Ref. [2]. 
in the presence of sulfur, the competition and combination of the two components dominate while the electron density has a very minor influence on the nucleation of $\mathrm{PbS}$ on the surface of $\mathrm{Au}$. Sulfur plays the role of fusing the nanoparticles together. Regardless of what solvent was used in the synthesis, the morphology is mostly determined by the amount of precursor reacting with the seed nanoparticles.

When the dumbbell-like $\mathrm{Au}-\mathrm{Fe}_{3} \mathrm{O}_{4}$ nanoparticles were heated to $150-200{ }^{\circ} \mathrm{C}$ in the presence of elemental sulfur, each pair of the S-modified Au nanoparticles at that high temperature would fuse together to give the $\mathrm{Fe}_{3} \mathrm{O}_{4}-\mathrm{Au}-\mathrm{Fe}_{3} \mathrm{O}_{4}$ ternary hybrid nanoparticles (Fig. 1(c)) [2]. $\mathrm{PbS}-\mathrm{Au}-\mathrm{Fe}_{3} \mathrm{O}_{4}$ nanoparticles could also be made by the reaction of $\mathrm{Au}-\mathrm{Fe}_{3} \mathrm{O}_{4}$ nanoparticles with a $\mathrm{Pb}$-oleate complex in the presence of elemental sulfur.

\section{Influence of lattice mismatch on morphology}

In addition to the polarity of the reaction solvent, the lattice mismatch between the two components is another critical factor in the successful synthesis of dumbbell-like nanoparticles.

\subsection{Influence on epitaxial growth}

Most of the dumbbell-like nanoparticles are prepared though epitaxial growth of one component nanoparticle on another component nanoparticle. It is commonly believed that in most cases the lattice mismatch between the two components should be below $5 \%$ for epitaxial growth to occur [48]. That is why Au and Ag (lattice mismatch: $0.2 \%$ ), Pt and Pd (lattice mismatch: $0.85 \%$ ) and other noble metals which have little lattice mismatch with each other have been widely reported for the synthesis of bimetallic nanocrystals with a core-shell structure [47]. With little lattice mismatch, epitaxial growth is more easily to occur and one metal component can have more chances to grow on another metal component, giving core-shell nanoparticles. As mentioned in the above sections, the preparation of dumbbell-like nanoparticles is similar to that of core-shell nanoparticles. Both of them can be synthesized through seeded growth involving preferential growth on a preformed seed surface. Seeded growth is widely used for its advantages in structural control and variety $[48,49]$. In seeded growth there are two patterns: homogeneous growth and heterogeneous growth. In homogeneous growth the whole seed surface acts as the nucleation site, but in heterogeneous growth, the growth can only occur on part of the seed surface [49-52]. These two patterns could often influence the shape and structure of the final nanoparticles. Core-shell nanoparticles are mostly generated from homogeneous growth and dumbbell-like nanoparticles form mostly as a result of heterogeneous growth [3,53-57]. For the preparation of dumbbell-like nanoparticles, heterogeneous growth could possibly occur when the lattice mismatch is not too large to break the epitaxial growth, which will produce individual nanoparticles, but should still be larger than that of homogeneous growth, which always generates core-shell nanoparticles. The different conditions for these two growth patterns are generally accept- ed by many researchers and have been proven by a large amount of experimental results [3,49-57].

\subsection{Experimental evidence of the influence of lattice mismatch}

Zhang et al. [26] prepared $\mathrm{Ag}-\mathrm{Fe}_{3} \mathrm{O}_{4}$ heterodimeric nanoparticles through epitaxial growth of $\mathrm{Ag}$ on $\mathrm{Fe}_{3} \mathrm{O}_{4}$ seeds in nonpolar solution. Silver acetate $[\mathrm{Ag}(\mathrm{ac})]$ was used as the $\mathrm{Ag}$ precursor and mixed with the as-prepared $\mathrm{Fe}_{3} \mathrm{O}_{4}$ nanoparticles in oleylamine and toluene. The reaction mixture was heated to $80{ }^{\circ} \mathrm{C}$ and kept at that temperature for $8 \mathrm{~h}$. The Ag nanoparticles grew on the $\mathrm{Fe}_{3} \mathrm{O}_{4}$ nanoparticles giving dumbbell-like nanoparticles. The authors pointed out that the large lattice mismatch between $\mathrm{Ag}$ (FCC, $a=4.08 \AA$ ) and $\mathrm{Fe}_{3} \mathrm{O}_{4}$ (FCC, $a=8.40 \AA$ ) could result in the formation of the non-symmetric heterodimer structure instead of the centrosymmetric core-shell type structure. This is similar to the $\mathrm{Au}-\mathrm{Fe}_{3} \mathrm{O}_{4}$ nanoparticles, where the authors [3] believed that the structure was derived from the epitaxial growth of $\mathrm{Fe}_{3} \mathrm{O}_{4}$ on $\mathrm{Au}$ seeds because $\mathrm{Au}$ has an FCC structure with $a=4.08 \AA$, whereas $\mathrm{Fe}_{3} \mathrm{O}_{4}$ has a cubic structure with $a=8.35 \AA$, which is almost exactly double. Even though Jin's group [47] succeeded in synthesizing $\mathrm{Pd@Cu}$ core-shell nanocubes through epitaxial growth, the $\mathrm{Cu}$ atoms initially nucleated on only a few of the many faces of the $\mathrm{Pd}$ seed. Furthermore, the final Pd seed was rarely located in the center of each core-shell structure, which was a result of the large lattice mismatch (7.1\%) between $\mathrm{Pd}$ and $\mathrm{Cu}$.

Another experiment conducted by $\mathrm{Gu}$ et al. [11] further demonstrates the strong influence of lattice mismatch on the formation of dumbbell-like nanoparticles. They reported a one-pot chemical synthesis method for generating dumbbell-like heterodimer nanoparticles by taking advantage of lattice mismatching and selective annealing at a relatively low temperature. First, amorphous CdS was deposited on the surface of FePt nanoparticles forming a metastable core-shell structure. The CdS could be transform from an amorphous to a crystalline state by heating the core-shell nanoparticles to 280 ${ }^{\circ} \mathrm{C}$. When they were dispersed in solution, the FePt@CdS core-shell nanoparticles evolved into dumbbell-like nanoparticles composed of CdS and FePt nanocrystals, and had sizes of less than $10 \mathrm{~nm}$. This was attributed to the incompatible lattices of FePt and CdS and the help of the surface tension. Scheme 5 [11] illustrates the typical synthetic route of the change from core-shell to a dumbbell-like structure.

From the high-resolution TEM images, they found that the

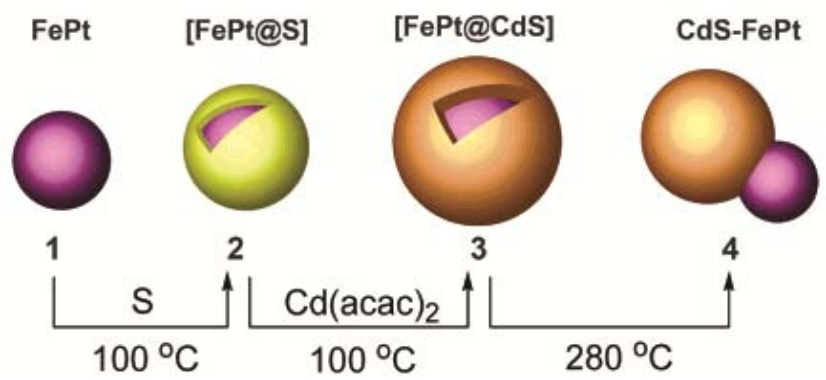

Scheme 5. The change from a core-shell to dumbbell-like structure. Reproduced with permission from Ref. [11]. 
dumbbell-like nanoparticles were almost monodisperse after the reaction was completed. The diameters of the FePt parts remained at $2.5 \mathrm{~nm}$ and the CdS parts had diameters of about 3 to $4 \mathrm{~nm}$. The selective area electron diffraction image of the dumbbell-like nanoparticles gave the rings that originated from the zinc blende phase of CdS $(\{111\},\{220\}$, and $\{311\}$ planes $)$ and the disordered FCC phase of FePt $(\{111\},\{200\},\{220\}$, and $\{311\}$ planes). They concluded that the key factors in making dumbbell-like nanoparticles are the lattice mismatch and the phase transition. That is why they failed to produce large amounts of well-defined FePt@S and FePt@CdS core-shell nanoparticles.

\subsection{Influencing mechanism of lattice mismatch and method to overcome this influence}

The reason for the influence of lattice mismatch may be explained from the system energy [58]. For two components that have a larger lattice mismatch, it is hard to form the bond between them because that requires more energy. Therefore, if they are combined in a dumbbell-like structure, the interface between them will be smaller and the system energy can thus be lower. If the lattice mismatch is smaller, the interface energy is not so high and it is possible to form a core-shell structure. That is why noble metals or semiconductors easily form core-shell structures, whereas dumbbell-like structures are easily formed between noble metals and semiconductors.

It is also worth noting that the addition of foreign ions (such as $\mathrm{Ag}^{+}$ions) may overcome the lattice mismatch in some reactions. The added foreign ions could form a sacrificial metal layer on the surface of the seed particles, and then another metal will replace the sacrificial metal through under-potential deposition (UPD) [59]. In the controlled overgrowth of Pd on $\mathrm{Au}$ nanorods, Jing et al. [60] introduced $\mathrm{Ag}^{+}$and $\mathrm{H}_{2} \mathrm{PdCl}_{4}$ into colloidal $\mathrm{Au}$ nanorods in the presence of cetyltrimethylammonium chloride or cetyltrimethylammonium bromide at $30{ }^{\circ} \mathrm{C}$, and then added ascorbic acid as the reducing agent to initiate the Ag-UPD guided deposition of Pd. When the concentration of $\mathrm{Ag}^{+}$was low, continuous conformal Pd shells were overgrown on the $\mathrm{Au}$ nanorods; with the increase of the $\mathrm{Ag}^{+}$concentration, small cavities started to form at the $\mathrm{Au}$-Pd interfaces; after the $\mathrm{Ag}^{+}$concentration was sufficiently high, segregated Pd islands started to form on the Au nanorods. It is believed that foreign ions, such as $\mathrm{Ag}^{+}$, play crucial roles in the growth control and various $\mathrm{Au}$ nanostructures can be made using this strategy during the seed-mediated growth processes [61-63].

In this $\mathrm{Ag}^{+}$-mediated Pd overgrowth, the sacrificial Ag monolayer formed on the Au nanorod first, and then reacted with $\mathrm{PdCl}_{4}{ }^{2-}$ ions through galvanic replacement. After that the Ag layer was consumed but continuously regenerated in the solution. With the co-reduction and co-deposition of $\mathrm{Ag}$ and $\mathrm{Pd}, \mathrm{Pd}$ successfully grew on the Au nanorods. Another example using sacrificial material for the synthesis of $\mathrm{Au}-\mathrm{CdSe}$ is discussed in the next section.

\section{Influence of surfactant concentration on morphology}

We discussed above that the reaction solvent could influence the morphology of dumbbell-like nanoparticles because different solvents with different polarities have various abilities to give electrons. A surfactant could also influence the morphology of dumbbell-like nanoparticles. The Au-CdSe nanoparticles synthesized by Carbone's group [64] could provide proof. Even though the $\mathrm{CdSe}$ in the $\mathrm{Au}-\mathrm{CdSe}$ nanoparticles was rod-like, the formation of the matchstick-like nanocrystals is still worth understanding for the synthesis of dumbbell-like nanoparticles. It is not easy to grow Au domains onto specific locations of CdSe nanoparticles, so the authors performed a two-step reaction to obtain $\mathrm{Au}-\mathrm{CdSe}$. First, they synthesized $\mathrm{PbSe}-\mathrm{CdSe}$ nanoparticles, in which $\mathrm{PbSe}$ was located at the tips of the CdSe nanorod. The PbSe was used as a sacrificial material in the next step. Second, these PbSe nanoparticles were replaced by $\mathrm{Au}$ nanoparticles using the Au(III):surfactant complex, which was prepared by dissolving $\mathrm{HAuCl}_{4}$, n-dodecylamine (DDA) and didodecyldimethyl-ammonium bromide (DDAB) in toluene by sonication. When the Au(III) amount was not too high, $\mathrm{Au}-\mathrm{CdSe}-\mathrm{Au}$ nanodumbbells were formed. Upon reaction with excess $\mathrm{Au}(\mathrm{III})$, the CdSe nanorods became thinner and shorter, and the $\mathrm{Au}$ nanoparticles were only located on one end of the CdSe nanorod (Fig. 5(a)) because of intraparticle Ostwald ripening mechanism, which can lead to the dissolution of the most unstable metal patches.

What is important is that by varying the concentration of the surfactants that bind to the gold surface, the author could change the morphology of the Au-CdSe nanoparticles. For example, with the Au(III):surfactant complex lacking DDA, they obtained a disordered network of nanorod chain-like segments (Fig. 5(b)), in which individual dumbbells fused with each other owing to the interaction and coalescing of the Au nanoparticles. With the surfactant containing only DDAB, the Au metal could still deposit on CdSe by an efficient reaction with PbSe sacrificial domains. The DDAB served as a reducing agent for Au(III), and the DDA served as a surface stabilizer for the gold nanoparticles. Without DDA, nanocrystal precipitation would happen and the gold meatal nanocrystals would be destabilized, forming the fused hybrid nanocrystals.

In several of the methods $[2,3,25,42]$ discussed in this review, oleylamine and oleic acid were frequently used as protective ligands. In actual fact, oleic acid was mostly used to enhance the reducing power of some reducing agents [65], and oleylamine served as the real stabilizing surfactant. Using only oleic acid might result in a sticky product that is difficult to purify [42].
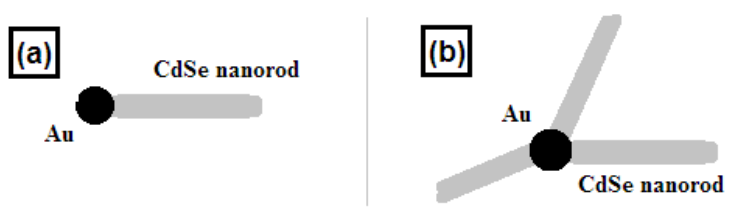

Fig. 5. Structural images of asymmetric semiconductor-gold hetero-structure (a) and fused $\mathrm{Au}-\mathrm{CdSe}$ nanoparticles (b) by changing the concentration of the surfactants. Reproduced with permission from Ref. [64]. 


\section{Conclusions}

With unique electronic, magnetic, optical, and catalytic properties, the dumbbell-like nanoparticles have great potential for the development of highly active catalysts for energy conversion and highly sensitive delivery probes for biomedical applications. However, in the field of catalytic combustion, the application of dumbbell-like nanoparticles is very limited. Only easily oxidized gases such as CO have been catalyzed using dumbbell-like nanostructured catalysts. The catalytic combustion of other gases at lower temperatures, such as methane, which is more difficult to oxidize, has yet to be achieved. This is because the components used to synthesize dumbbell-like nanoparticles are very limited. Because of the limitations of the current synthesis methods, only a few elements have been used in the past, and even with these elements it is not easy to successfully synthesize the dumbbell-like structure.

Many factors can influence the result in the synthesis of dumbbell-like nanoparticles. The control of the epitaxial growth could be affected by the seed size and size ratio; a smaller seed size and size difference between the two components is favorable for the control of the reaction. The reaction temperature and reaction time should be carefully controlled based on the properties of the reaction materials to obtain dumbbell-like nanoparticles with an appropriate component size and size distribution. The morphology of the dumbbell-like nanoparticles, which is most important for the unique physical and chemical properties, could be influenced by a variety of factors, such as the polarity of the reaction solvent, the ratio of the precursors correlating with the two components in the dumbbell-like structure, the lattice mismatch between the two materials of the dumbbell-like nanoparticles, and the surfactant concentration used in synthesizing the dumbbell-like nanoparticles. In addition to those factors, suitable precursors and reducing or oxidizing agents, the operating environment, and many other factors can determine the result in the synthesis of dumbbell-like nanoparticles. It will be meaningful to discover other synthetic methods to obtain dumbbell-like nanoparticles consisting of more element species and to study the applications of this uniquely structured catalysts for the catalytic combustion of more gases.

\section{References}

[1] C. Wang, C. J. Xu, H. Zeng, S. H. Sun, Adv. Mater., 2009, 21, 3045-3052.

[2] W. L. Shi, H. Zeng, Y. Sahoo, T. Y. Ohulchanskyy, Y. Ding, Z. L. Wang, M. Swihart, P. N. Prasad, Nano Lett., 2006, 6, 875-881.

[3] H. Yu, M. Chen, P. M. Rice, S. X. Wang, R. L. White, S. H. Sun, Nano Lett., 2005, 5, 379-382.

[4] R. Costi, G. Cohen, A. Salant, E. Rabani, U. Banin, Nano Lett., 2009, 9, 2031-2039.

[5] A. Wood, M. Giersig, P. Mulvaney, J. Phys. Chem. B, 2001, 105, 8810-8815.

[6] M. Haruta, Gold Bull., 2004, 37, 27-36.

[7] Y. Q. Li, Q. Zhang, A. V. Nurmikko, S. H. Sun, Nano Lett., 2005, 5, 1689-1692.

[8] A. Figuerola, A. Fiore, R. Di Corato, A. Falqui, C. Giannini, E. Micotti,
A. Lascialfari, M. Corti, R. Cingolani, T. Pellegrino, J. Am. Chem. Soc., 2008, 130, 1477-1487.

[9] T. Teranishi, A. Wachi, M. Kanehara, T. Shoji, N. Sakuma, M. Nakaya, J. Am. Chem. Soc., 2008, 130, 4210-4211.

[10] N. A. Frey, M. H. Phan, H. Srikanth, S. Srinath, C. Wang, S. Sun, J. Appl. Phys., 2009, 105, 07B502.

[11] H. W. Gu, R. K. Zheng, X. X. Zhang, B. Xu, J. Am. Chem. Soc., 2004, $126,5664-5665$.

[12] J. Jiang, H. W. Gu, H. L. Shao, E. Devlin, G. C. Papaefthymiou, J. Y. Ying, Adv. Mater., 2008, 20, 4403-4407.

[13] K. W. Kwon, M. Shim, J. Am. Chem. Soc., 2005, 127, 10269-10275.

[14] Y. Wei, R. Klajn, A. O. Pinchuk, B. A. Grzybowski, Small, 2008, 4, 1635-1639.

[15] E. Elmalem, A. E. Saunders, R. Costi, A. Salant, U. Banin, Adv. Mater., 2008, 20, 4312-4317.

[16] C. Wang, H. Daimon, S. Sun, Nano Lett., 2009, 9, 1493-1496.

[17] H. W. Gu, Z. M. Yang, J. H. Gao, C. K. Chang, B. Xu, J. Am. Chem. Soc., 2005, 127, 34-35.

[18] J. S. Choi, Y. W. Jun, S. I. Yeon, H. C. Kim, J. S. Shin, J. Cheon, J. Am. Chem. Soc., 2006, 128, 15982-15983.

[19] Z. Ma, S. Dai, Nano Res., 2011, 4, 3-32.

[20] A. A. Herzing, C. J. Kiely, A. F. Carley, P. Landon, G. J. Hutchings, Science, 2008, 321, 1331-1335.

[21] A. Stephen K. Hashmi, G. J. Hutchings, Angew. Chem. Int. Ed., 2006, 45, 7896-7936.

[22] L. M. Molina, B. Hammer, Phys. Rev. Lett., 2003, 90, 206102/1206102/4.

[23] Z. P. Liu, X. Q. Gong, J. Kohanoff, C. Sanchez, P. Hu, Phys. Rev. Lett., 2003, 91, 266102/1-266102/4.

[24] S. Laursen, S. Linic, Phys. Rev. Lett., 2006, 97, 026101/1026101/4.

[25] C. Wang, H. F. Yin, S. Dai, S. H. Sun, Chem. Mater., 2010, 22, 3277-3282.

[26] L. Zhang, Y. H. Dou, H. C. Gu, J. Colloid Interface Sci., 2006, 297, 660-664.

[27] H. F. Yin, C. Wang, H. G. Zhu, S. H. Overbury, S. H. Sun, S. Dai, Chem. Commun., 2008, 4357-4359.

[28] Y. Lee, M. A. Garcia, N. A. Frey Huls, S. H. Sun, Angew. Chem. Int. Ed., 2010, 49, 1271-1274.

[29] X. Q. Huang, Y. J. Li, H. L. Zhou, X. Zhong, X. F. Duan, Y. Huang, Chem.-Eur. J., 2012, 18, 9505-9510.

[30] X. W. Xie, Y. Li, Z. Q. Liu, M. Haruta, W. J. Shen, Nature, 2009, 458, 746-749.

[31] S. Carrettin, P. McMorn, P. Johnston, K. Griffin, C. J. Kiely, G. A. Attard, G. J. Hutchings, Top. Catal., 2004, 27, 131-136.

[32] R. Zanella, C. Louis, S. Giorgio, R. Touroude, J. Catal., 2004, 223, 328-339.

[33] C. Milone, R. Ingoglia, S. Galvagno, Gold Bull., 2006, 39, 54-65.

[34] A. Abad, A. Corma, H. García, Pure Appl. Chem., 2007, 79, 1847-1854.

[35] A. Corma, P. Concepción, P. Serna, Angew. Chem. Int. Ed., 2007, 46, 7266-7269.

[36] A. Corma, P. Serna, H. García, J. Am. Chem. Soc., 2007, 129, 6358-6359.

[37] H. Zeng, J. Li, J. P. Liu, Z. L. Wang, S. H. Sun, Nature, 2002, 420, 395-398.

[38] C. J. Kiely, J. Fink, M. Brust, D. Bethell, D. J. Schiffrin, Nature, 1998, 396, 444-446.

[39] S. Peng, Y. Lee, C. Wang, H. F. Yin, S. Dai, S. H. Sun, Nano Res., 2008, 1, 229-234.

[40] V. K. LaMer, R. H. Dinegar, J. Am. Chem. Soc., 1950, 72, 4847-4854.

[41] C. B. Murray, C. R. Kagan, M. G. Bawendi, Annu. Rev. Mater. Sci., 


\title{
Graphical Abstract
}

Chin. J. Catal., 2016, 37: 681-691 doi: 10.1016/S1872-2067(15)61069-5

\section{A review of significant factors in the synthesis of hetero-structured dumbbell-like nanoparticles}

Qifu Huang, Wenzhi Li *, Qizhao Lin *, Dong Pi, Chao Hu, Chunyu Shao, Haitao Zhang

University of Science and Technology of China

This article reviews some significant factors in the synthesis of dumbbell-like nanoparticles, including seed size and size ratio, reaction temperature and time, solvent polarity, precursor ratio, lattice mismatch, and surfactant concentration.

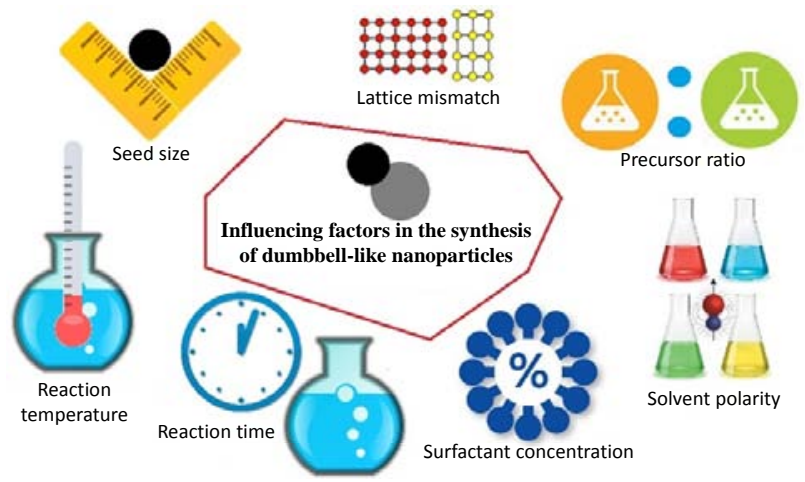

2000, 30, 545-610.

[42] S. H. Sun, H. Zeng, D. B. Robinson, S. Raoux, P. M. Rice, S. X. Wang, G. Li, J. Am. Chem. Soc., 2004, 126, 273-279.

[43] S. H. Sun, H. Zeng, J. Am. Chem. Soc., 2002, 124, 8204-8205.

[44] Y. Lin, H. Skaff, T. Emrick, A. D. Dinsmore, T. P. Russell, Science, 2003, 299, 226-229.

[45] A. D. Dinsmore, M. F. Hsu, M. G. Nikolaides, M. Marquez, A. R. Bausch, D. A. Weitz, Science, 2002, 298, 1006-1009.

[46] X. L. Sun, S. J. Guo, Y. Liu, S. H. Sun, Nano Lett., 2012, 12 , 4859-4863.

[47] M. S. Jin, H. Zhang, J. G. Wang, X. L. Zhong, N. Lu, Z. Y. Li, Z. X. Xie, M. J. Kim, Y. N. Xia, ACS Nano, 2012, 6, 2566-2573.

[48] F. R. Fan, D. Y. Liu, Y. F. Wu, S. Duan, Z. X. Xie, Z. Y. Jiang, Z. Q. Tian, J. Am. Chem. Soc., 2008, 130, 6949-6951.

[49] Y. H. Chen, H. H. Hung, M. H. Huang, J. Am. Chem. Soc., 2009, 131, 9114-9121.

[50] J. Jung, D. Seo, G. Park, S. Ryu, H. Song, J. Phys. Chem. C, 2010, 114, 12529-12534.

[51] D. Seo, J. H. Park, J. Jung, S. M. Park, S. Ryu, J. Kwak, H. Song, J. Phys. Chem. C, 2009, 113, 3449-3454.

[52] N. R. Sieb, N. Wu, E. Majidi, R. Kukreja, N. R. Branda, B. D. Gates, ACS Nano, 2009, 3, 1365-1372.
[53] W. W. He, X. C. Wu, J. B. Liu, K. Zhang, W. G. Chu, L. L. Feng, X. N. Hu, W. Zhou, S. S. Xie, J. Phys. Chem. C, 2009, 113, 10505-10510.

[54] F. Wetz, K. Soulantica, A. Falqui, M. Respaud, E. Snoeck, B. Chaudret, Angew. Chem. Int. Ed., 2007, 46, 7079-7081.

[55] L. Carbone, P. D. Cozzoli, Nano Today, 2010, 5, 449-493.

[56] J. T. Zhang, Y. Tang, K. Lee, M. Ouyang, Science, 2010, 327, 1634-1638.

[57] N. E. Motl, J. F. Bondi, R. E. Schaak, Chem. Mater., 2012, 24, 1552-1554.

[58] Y. Yang, W. F. Wang, X. L. Li, W. Chen, N. N. Fan, C. Zou, X. Chen, X. J. Xu, L. J. Zhang, S. M. Huang, Chem. Mater., 2013, 25, 34-41.

[59] S. R. Brankovic, J. X. Wang, R. R. Adžić, Surf. Sci., 2001, 474, L173-L179.

[60] H. Jing, H. Wang, CrystEngComm, 2014, 16, 9469-9477.

[61] B. Nikoobakht, M. A. El-Sayed, Chem. Mater., 2003, 15, 1957-1962.

[62] T. Ming, W. Feng, Q. Tang, F. Wang, L. D. Sun, J. F. Wang, C. H. Yan, J. Am. Chem. Soc., 2009, 131, 16350-16351.

[63] J. Zhang, M. R. Langille, M. L. Personick, K. Zhang, S. Y. Li, C. A. Mirkin, J. Am. Chem. Soc., 2010, 132, 14012-14014.

[64] L. Carbone, S. Kudera, C. Giannini, G. Ciccarella, R. Cingolani, P. D. Cozzoli, L. Manna, J. Mater. Chem., 2006, 16, 3952-3956.

[65] R. Sato, M. Kanehara, T. Teranishi, Small, 2011, 7, 469-473.

\section{异质哑铃型纳米颗粒合成中的关键因素}

\author{
黄启福, 李文志, 林其钢”, 皮冬, 胡 超, 郡春宇, 张海涛 \\ 中国科学技术大学工程科学学院热科学和能源工程系, 安徽合肥 230026
}

摘要: 哑铃型纳米颗粒由一种包含强相互作用的异质结构成, 它两端是不同物质的纳米颗粒. 这两种不同功能的纳米颗粒 紧密相连, 形成一种亚铃形的外观. 这种结构的纳米颗粒在电子、磁性、光学及催化等方面有着不同于单一组分纳米颗粒 的独特性质, 因此受到人们广泛关注. 哑铃型纳米颗粒的这些独特性质是由两种物质交界面处的电子转移引起的, 得益于 较强的界面相互作用, 两种物质都可以通过界面处的电子转移得到改良, 使得这种结构的催化剂在较低温度下催化氧化有 机废气时活性很高. 以 $\mathrm{CO}$ 氧化反应为例, $\mathrm{Au}$ 纳米颗粒通常情况下对该反应没有催化活性, 但是被负载到金属氧化物上面 以后, 却表现出了很高的催化活性. 这正是氧化物载体与 $\mathrm{Au}$ 纳米颗粒之间电子传输的结果.

通常在核壳结构中, 核心物质以及两种物质的交界面都被外壳所包裹, 而哑铃型结构当中的两种物质的功能面以及它 们之间活泼的交界面均可以充分地暴露在反应物中, 从而极大提升了其催化效果. 这种独特的结构优势也在疾病诊断与 治疗中的多功能探针上得到了广泛应用. 由于哑铃型结构的两种物质的纳米颗粒相对位置是固定的, 当用作催化剂时可 以发挥出很好的抗烧结性能, 还可使这两种物质更协调地均匀分布. 因此哑铃型结构催化剂不仅催化活性更高, 而且在较 高温度下具有较高的稳定性. 
哑铃型结构可以看作是独立纳米颗粒与核壳型纳米颗粒之间的一种中间状态, 它通常是由一种物质的纳米颗粒在另 一种种子颗粒上面经过外延生长得到的. 这与核壳结构纳米颗粒的合成很相似, 但是必须准确地控制成核过程, 使得成核 可以各向异性地发生在种子颗粒的某一个晶面上. 而在核壳结构的合成中, 这一成核过程是均匀分布的. 所以在制备哑铃 型结构纳米颗粒时, 很重要的就是要促进非均质成核, 同时抑制均相成核.

由于哑铃型纳米颗粒的特殊结构, 在制备时想要准确控制上述成核条件是非常困难的, 所以到目前为止, 仅有很少种 类的物质可以被制成哑铃型结构, 比如 $\mathrm{Au}(\mathrm{Ag}, \mathrm{Pt}, \mathrm{Pd})-\mathrm{Fe}_{3} \mathrm{O}_{4}\left(\mathrm{Co}_{3} \mathrm{O}_{4}\right), \mathrm{Au}-\mathrm{PbS}(\mathrm{PbSe}), \mathrm{FePt}-\mathrm{CdS}$ 和Cu-Ag等, 这些物质中大多 数都是由贵金属纳米颗粒和磁性纳米粒子组成的. 哑铃型纳米颗粒由于受限于物质种类, 它在催化氧化方面的应用也被 局限在了很少一部分气体上, 如CO. 而通过其它很多种催化剂已经可以在较低温度(甚至零下数摄氏度)下实现CO催化氧 化. 因此, 哑铃型结构的优势在 $\mathrm{CO}$ 催化氧化中并不能得到很好利用和体现, 而用于甲烷等一些在较低温度下更难氧化的气 体的催化氧化尚未见报道. 这正是由合成多种多样的哑铃型纳米颗粒的巨大困难所致. 因此, 找到合成哑铃型纳米颗粒的 困难所在以及合成过程中的一些重要影响因素非常有意义, 这将帮助我们使用更多的物质合成出一些新的哑铃型纳米颗 粒, 进而利用其高催化活性, 使得更多难以氧化的气体在较低温度下被氧化.

本文总结了合成哑铃型纳米颗粒时的多种影响因素, 并介绍了相关的一些合成方法. 种子颗粒的尺寸以及两种颗粒之 间的尺寸比例可以影响制备过程中外延生长的可控性, 颗粒尺寸以及两种颗粒的尺寸差别越小, 反应越容易控制. 反应温 度和反应时间需要根据反应物的性质进行精确控制才可以得到合适的尺寸以及较好的粒径分布. 而两种不同的物质最终 能不能形成亚铃型结构则是由很多种因素决定的, 比如反应溶剂的极性、两种物质之间的晶格错配度以及反应中所用乳化 剂的含量. 除此之外, 合适的前驱体、氧化还原剂以及操作环境等都可以影响哑铃型纳米颗粒的合成结果.

关键词: 哑铃型纳米颗粒; 催化剂合成; 催化燃烧; 催化氧化

收稿日期: 2016-01-09. 接受日期: 2016-02-24. 出版日期: 2016-05-05.

*通讯联系人. 电话: (0551)63600786; 传真: (0551)63600786; 电子信箱: liwenzhi@ustc.edu.cn

通讯联系人. 电话: (0551)63600430; 电子信箱: qlin@ustc.edu.cn

基金来源：国家自然科学基金(51376171); 安徽省杰出青年科学基金(1508085J01).

本文的英文电子版由Elsevier出版社在ScienceDirect上出版(http://www.sciencedirect.com/science/journal/18722067). 